\title{
Effects of meteorological and atmospheric conditions on night sky brightness
}

\author{
D. E. Lolkema ${ }^{1}$, M. Haaima ${ }^{1}$, P. N. den Outer $^{1}$ \& H. Spoelstra ${ }^{2,3}$ \\ ${ }^{I}$ National Institute for Public Health and the Environment, \\ The Netherlands \\ ${ }^{2}$ KEMA, The Netherlands \\ ${ }^{3}$ Lumineux Consult, The Netherlands
}

\begin{abstract}
Although the need for artificial light in populated areas is beyond question, there are also adverse effects of night lighting on flora and fauna as well as on humans. The actual effect however, can only be known with information about the exposure of flora, fauna and humans, i.e. the night sky brightness. But what are the night sky brightness levels? Night sky brightness strongly depends, apart from the surrounding light sources, on the meteorological and atmospheric conditions. The sky close to a strong light source like a greenhouse, a large city or an industrial area, can still be quite dark on clear nights, i.e. without clouds or an optically thick aerosol layer. But on cloudy nights this same sky can be very bright due to light scattering by these same clouds. Monitoring light emission by future satellites is therefore not enough. The effects of meteorological and atmospheric conditions on the night sky brightness need to be known. Continuous sky brightness measurements are being performed at the Cabauw Experimental Site for Atmospheric Research (CESAR) since February 2010. At this site, a high number of different meteorological and atmospheric parameters are monitored. The first analysis over the year 2010 focused on the comparison of sky brightness to cloud-base height, cloud cover and aerosol data. The first results are presented in this paper.
\end{abstract}

Keywords: night sky brightness, artificial lighting, light pollution, luminance, meteorological conditions, Cabauw, CESAR. 


\section{Introduction}

Since the invention of the light bulb our world at night has become far brighter. Artificial lighting enables us to extend our activities well into naturally dark hours. Streets are lit, we can perform our favourite sports outdoors, and industry and transportation run twenty-four hours a day. All these activities make use of light to a large extend and consequently may illuminate the surroundings up to tens of kilometers. However, there are also adverse effects of lighting at night on flora, fauna and humans [1-4], which will be further investigated in the Dutch projects 'Light Pollution and the Absence of Darkness' (LightPAD) by the National Institute for Public Health and the Environment (RIVM), 'Impact of artificial light on flora and fauna in The Netherlands' by Wageningen University and Research Centre and the German project 'Verlust der Nacht', amongst others. To know the impact of artificial night lighting on flora, fauna and humans, apart from the effects, also the exposure of flora, fauna and humans to artificial night lighting needs to be known.

Levels of night light emission can be measured with space-borne sensors and is currently being done by the Defense Meteorological Satellite Program Operational Linescan System (DMSP-OLS) [5-7] and in the near future by the Visible and Infrared Imaging System (VIIRS) satellite sensor onboard The NASA National Polar-orbiting Operational Environmental Satellite System (NPOESS) Preparatory Project (NPP) [8, 9]. The latter will largely improve the quality of the night lighting observations. Both sensors monitor the light emission. However, the exposure of flora, fauna and humans to night lighting is likely better defined by the night sky brightness, i.e. the luminance at zenith during night. The level of night sky brightness strongly depends, apart from the surrounding light sources, on the meteorological and atmospheric conditions. The sky close to a strong light source like a greenhouse, a large city or an industrial area, can still be quite dark on clear nights, i.e. without clouds or an optically thick aerosol layer. But on cloudy nights, this same sky can be very bright due to scattering of light by these same clouds. Although the International Commission on Illumination (CIE) has defined a set of outdoor daylight conditions linking sunlight and skylight for theoretical and practical purposes, listing a set of luminance distributions which model the sky under a wide range of conditions from the heavily overcast sky to cloudless weather [10], the night sky brightness under different meteorological and atmospheric conditions is not well known, i.e. the luminances during night are not well known.

In a pilot study we have investigated the effects of meteorological and atmospheric conditions on the night sky brightness. We have performed continuous measurements of night sky brightness at the Cabauw Experimental Site for Atmospheric Research (CESAR [11]) for a one-year period. At CESAR, a large number of meteorological and atmospheric properties are already monitored. For our first analysis, we focussed on the correlations of night sky brightness with cloud-base height, cloud cover, particulate matter mass concentrations and horizontal visibility. The results are presented in this paper. 
Night light emission and night sky brightness can be linked and has be done by Treanor [12], Garstang [13], Falchi and Cinzano [14], Cinzano et al. [5-7] and Kerola [15]. The results of our study, and ongoing research within the project LightPAD, can be used to further validate and possibly improve these models, and thereby improve the knowledge on the exposure of flora, fauna and humans to artificial night sky brightness, based on light emission data.

\section{Instruments}

All analyses are based on measurements from the following instruments: DigiLum (luminance), Ceilometer (cloud-base height), APCADA (cloud cover), TEOM (PM mass concentration) and Vaisala (visibility). The instruments are located at CESAR and will be described in more details in the next sub-sections.

\subsection{DigiLum}

The DigiLum is a one-of-a-kind, special designed, luminance meter. It is capable of measuring luminance levels ranging from $0.25 \mathrm{mcd} / \mathrm{m}^{2}$ (night time levels) up to $2 \cdot 10^{7} \mathrm{mcd} / \mathrm{m}^{2}$ (typical daytime levels). The entrance optics of the detector consists of a tube of about $40 \mathrm{~cm}$ length that acts as a baffle for direct sunlight and a heated lens that images the light coming from zenith onto a solid state photocell. The entrance optics has a maximum entrance angle of $5^{\circ}$. The lens is heated in order to evaporate dew, rain drops and snow on the lens. During the winter of 2009/2010, which had a period with lots of snow, the lens stayed clear. The photocell is tuned to the photopic eye response CIE [16] and is equipped with a temperature sensor in order to correct for the temperature-dependent dark current, which is automatically subtracted from the signal of the photodetector. The dark current of the photodetector has been determined by the manufacturer for temperatures below $0^{\circ} \mathrm{C}$ up to $25^{\circ} \mathrm{C}$. A polynomial function has been inferred to fit the dark current. The DigiLum was initially calibrated by the manufacturer begin 2009 and has been recalibrated in August 2010. The difference between the two calibrations is only $6 \%$, which is regarded as quite good in this stage of maturity of the instrument.

\subsubsection{Spectral considerations}

Spectral responses of plants, animals and humans to light are not the same. The DigiLum is also used to validate modelled night sky brightness using the standard manufacturers lighting data from luminaires. As this data is based on the photopic eye response, the same spectral response was chosen for the DigiLum. It will be very interesting to investigate night radiances at different spectral wavelengths, but this is beyond the scope of this paper.

\subsection{Additional sensors}

Cloud-base height data have been obtained from a Vaisala LD40 Cloud-base Height Ceilometer [17]. It can measure the height of clouds up to an altitude of $13 \mathrm{~km}$ with a vertical resolution of 7.5 meter. It is installed 800 meters south 
from the location of the DigiLum. Cloud cover data have been obtained from the Automatic Partial Cloud Amount Detection Algorithm (APCADA, Duerr and Philipona [18]). APCADA is a real-time system delivering the cloud cover every 10 minutes, 24 hours a day. Thin high clouds (cirrus clouds) cannot be detected by APCADA. The cloud amount is expressed in octas, where a value of ' 0 ' indicates clouds not present and ' 8 ' a solid overcast. It is installed 500 meters south from the location of the DigiLum. Mass concentrations data of particulate matter with diameter sizes smaller than 10 micron (PM10) and smaller than 2.5 micron (PM2.5), have been obtained by a Tapered Element Oscillating Microbalance (TEOM) 1400a sensor unit [19] in combination with a Series8500 Filter Dynamics Measurement System (FDMS) monitor [20], installed close to the luminance measurements at an altitude of 3.5 meter. Finally, visibility data have been obtained from a Vaisala FD12P [21] weather sensor installed 500 meters south from the location of the DigiLum at an altitude of 1 meter.

\section{Location and data-sets}

\subsection{Cabauw experimental site for atmospheric research - CESAR}

Cabauw Experimental Site for Atmospheric Research (CESAR) is owned and maintained by the Royal Netherlands Meteorological Institute, KNMI [22], and home of the CESAR-consortium, a consortium of eight partners that perform advanced atmospheric research. A high number of atmospheric measurements is performed at the same location and synergy of measurements is the key. CESAR is located in the western part of the Netherlands. The surrounding landscape is quite open and consists of mainly pasture and small villages (number of residents in brackets). Two very small villages, Cabauw (700) and Lopik (5400), are located nearby at about $2 \mathrm{~km}$. The village Schoonhoven (12000) is located at $5 \mathrm{~km}$ distance and Gouda (71000) and Nieuwegein (61000) are located at a distance of some $12 \mathrm{~km}$ from the measurement site. Larger cities are located at a distance of $20 \mathrm{~km}$, Utrecht and $30 \mathrm{~km}$, Rotterdam. Closest illuminated highway is located at a distance of $6 \mathrm{~km}$. The position of the DigiLum is $51.9744^{\circ} \mathrm{N}$, $4.9233^{\circ} \mathrm{E}$.

\subsection{Data set restrictions}

Sky brightness measurements have been compared to cloud-base height data, cloud cover data, PM10 and PM2.5 mass concentration data, and visibility data. The data-sets cover the period February-November 2010. The comparison to cloud-base height has been restricted to the first cloud layer and Solar Elevation Angles (SEA) $<-15^{\circ}$, data have been averaged to minute-values. The comparison to cloud cover has been restricted also to SEAs $<-15^{\circ}$ and data have been averaged to 10-minute values. Finally, the comparison to mass concentrations of PM10 and PM2.5 and visibility has been restricted to SEAs $<-12^{\circ}$ and Moon Elevation Angles (MEA) $<0^{\circ}$. 

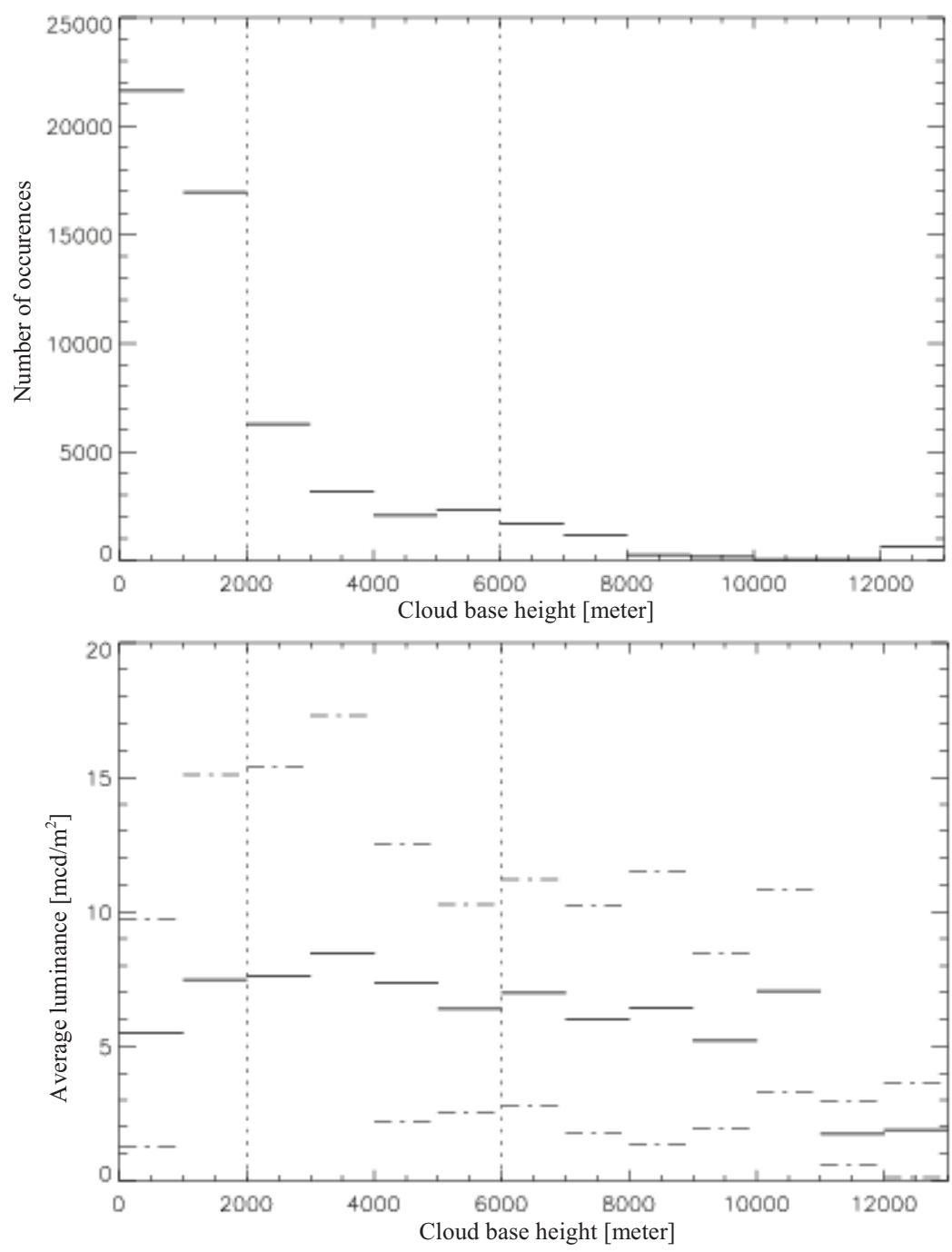

Figure 1: Top: distribution of the cloud-base height. Bottom: average luminance at zenith (solid lines) and its standard deviation by cloud-base height (dashed lines). The dotted vertical lines indicate the borders between the different cloud altitude ranges. Measurements: February-November 2010.

\section{Results}

\subsection{Cloud-base height}

We first address the distribution of the cloud-base height for the first cloud layer at Cabauw for the analysis period, Figure 1 (top). As can be seen, clouds 
are usually found in the low altitude range $(0-2 \mathrm{~km})$. In the same figure (bottom) we show the average luminance at zenith as a function of this same cloud-base height. With clouds present between 0 and $11 \mathrm{~km}$, the average luminance varies between 5 and $9 \mathrm{mcd} / \mathrm{m}^{2}$; only for clouds higher than $11 \mathrm{~km}$, the average luminance drops to less than $2 \mathrm{mcd} / \mathrm{m}^{2}$. Note the low number of datapoints below $8 \mathrm{~km}(<1000$ occurrences $)$. The distributions of the luminance at zenith for different cloud-base heights are shown in Figure 2. The cloud-base heights have been grouped as follows: no clouds, low altitude clouds $(0-2 \mathrm{~km})$, mid altitude clouds $(2-6 \mathrm{~km})$ and high altitude clouds $(6-$ $13 \mathrm{~km})$. When there are no clouds present, the distribution peaks at a rather low luminance level of $1.1 \mathrm{mcd} / \mathrm{m}^{2}$, with clouds present in the low altitude range, the distribution peaks at a higher luminance level of $3.7 \mathrm{mcd} / \mathrm{m}^{2}$. The distribution of clouds in the mid altitude range shows a broad peak around this same luminance level of $3.7 \mathrm{mcd} / \mathrm{m}^{2}$. The distribution of clouds in the high altitude range is rather flat.

\subsection{Cloud cover}

Figure 3 gives the averaged measured luminance at zenith as a function of cloud cover, expressed in octas. The subset with MEA $<0$ is indicated by squares. Clearly, the luminance at zenith increases with higher cloud fraction. This positive correlation is to be expected as an overcast sky reflects more upwelling light downwards to the detectors than a clear sky. The linear regression for the data set with MEA $<0$ yields a correlation coefficient of 0.93 . Figure 4 gives a distribution of the measured luminance at zenith per octa cloud cover, cf. Figure 2. At small octas the distribution peaks at a luminance of a little more than $1 \mathrm{mcd} / \mathrm{m}^{2}$. Moving towards higher octas, we observe a drop and broadening of this peak and an "in-grow" at the higher luminance bins. At an octa of eight, we practically do not observe measurements below $2 \mathrm{mcd} / \mathrm{m}^{2}$.

\subsection{Aerosols and visibility}

In Figure 5 the measured luminance at zenith as function of the PM10 and PM2.5 mass concentrations is plotted. A correlation between PM10 or PM2.5 and the luminance does not emerge. Also, a correlation between visibility and luminance at zenith is not found in our data set (not shown here). Note that the PM10 and PM2.5 mass concentrations used for this analysis are measured at an altitude of $3.5 \mathrm{~m}$. The question is how representative a single altitude measurement is, especially during the night when a well-mixed boundary layer extending up to several hundreds of meters is absent most of the time. In future analysis it will be far more interesting to compare sky brightness measurements with aerosol-information from other altitudes or column integrated information. 

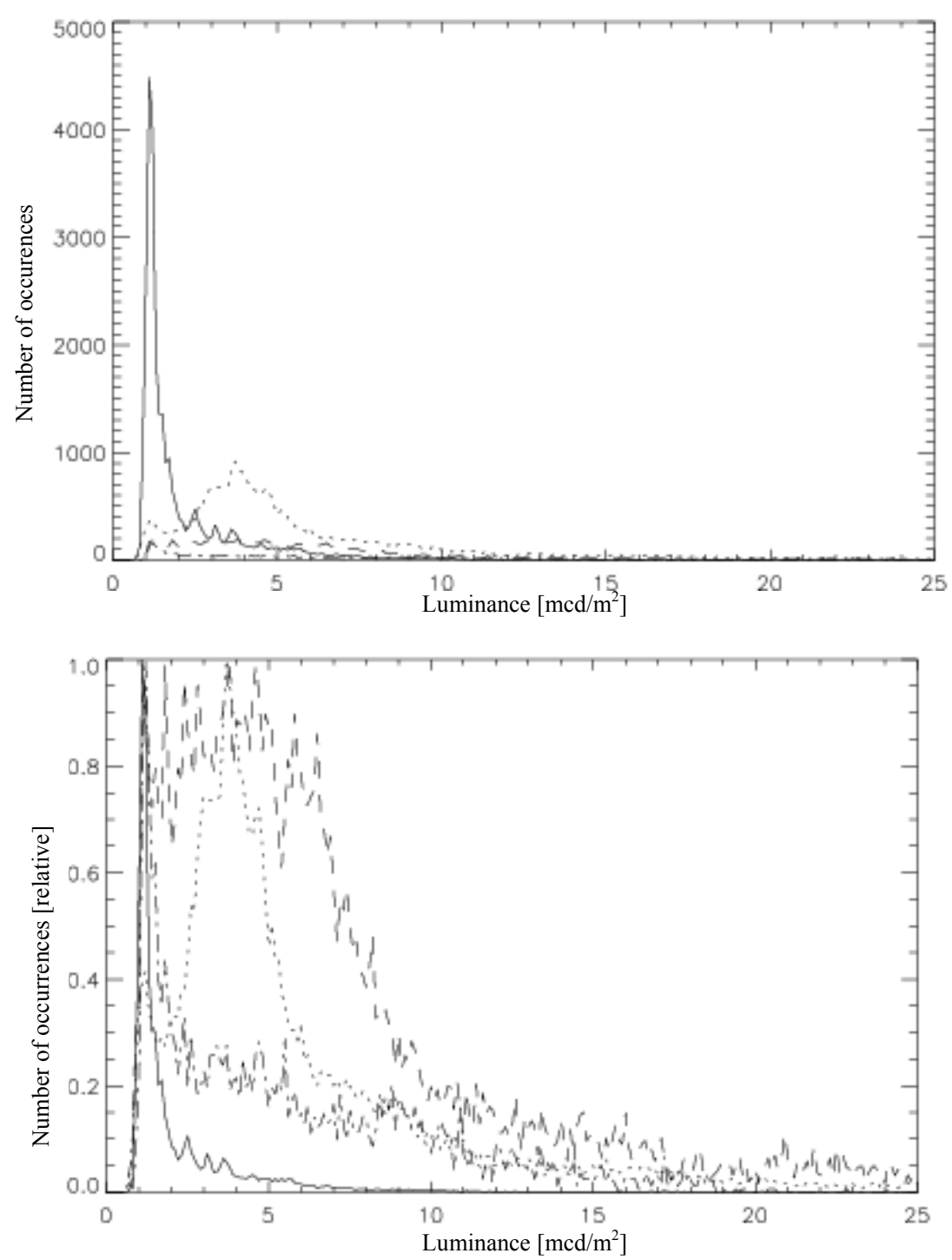

Figure 2: Distribution (top) and relative distribution (bottom) of the luminance at zenith for no clouds (solid line), low altitude clouds (dotted line), mid altitude clouds (dashed line) and high altitude clouds (dash dot line). Measurements: February-November 2010. 


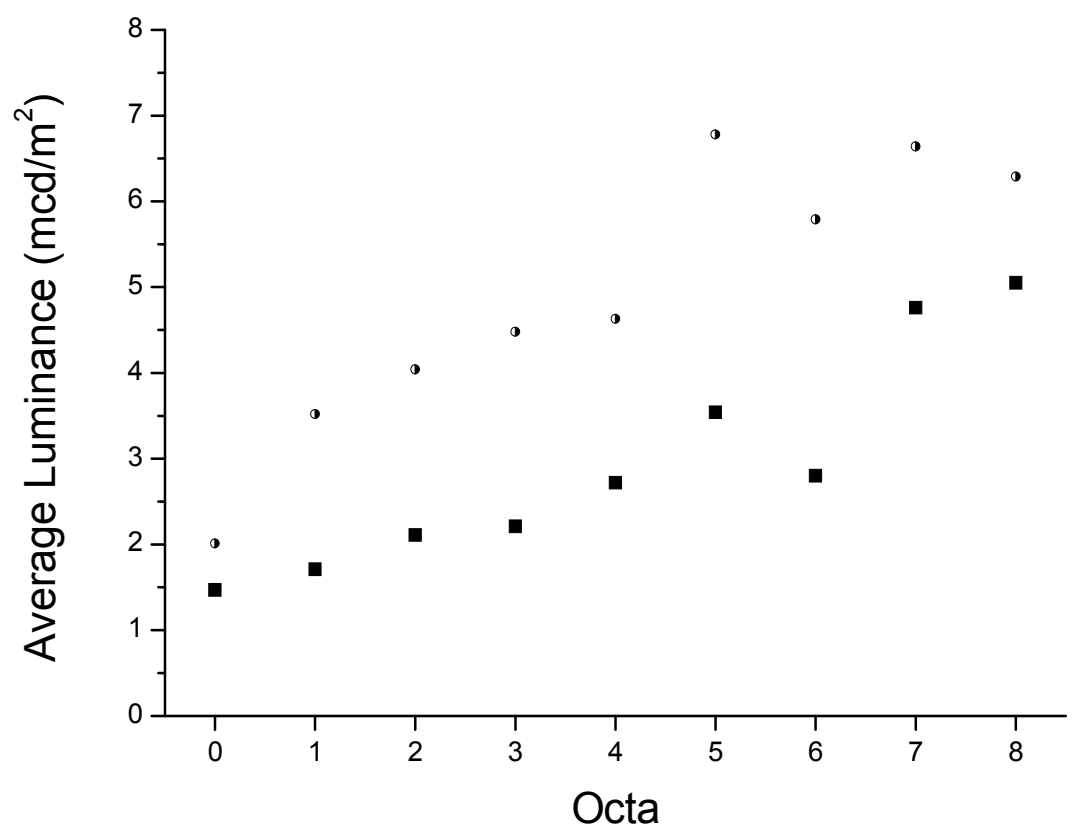

Figure 3: Average luminance at zenith as a function of cloud cover expressed in octas. Squares indicate data with Moon Elevation Angle (MEA) $<0$, dots indicate data with all MEAs.

\section{Conclusion}

At CESAR the luminance at zenith at clear nights is $1.1 \mathrm{mcd} / \mathrm{m}^{2}$. With clouds present between 0 en $11 \mathrm{~km}$ the average luminance at zenith increases to 5$9 \mathrm{mcd} / \mathrm{m}^{2}$. For clouds in the low altitude range (mostly present at CESAR), the distribution of the luminance at zenith peaks at $3.7 \mathrm{mcd} / \mathrm{m}^{2}$. The luminance at zenith drops to less than $2 \mathrm{mcd} / \mathrm{m}^{2}$ when clouds are above $11 \mathrm{~km}$. With respect to cloud cover, the luminance at zenith increases to first order linearly with increasing cloud cover, a correlation coefficient of 0.9 has been established. The distribution of the measured luminances shifts to higher values and broadens for increasing octas. At a solid overcast the distribution peaks at $4 \mathrm{mcd} / \mathrm{m}^{2}$. Relationships have not been found for the measured luminance to PM10 or PM2.5 mass concentrations, or to visibility at a 1 meter altitude.

The effects of meteorological and atmospheric properties on night sky brightness will be further investigated in the four-year project 'LightPAD - Light Pollution and the Absence of Darkness'. 

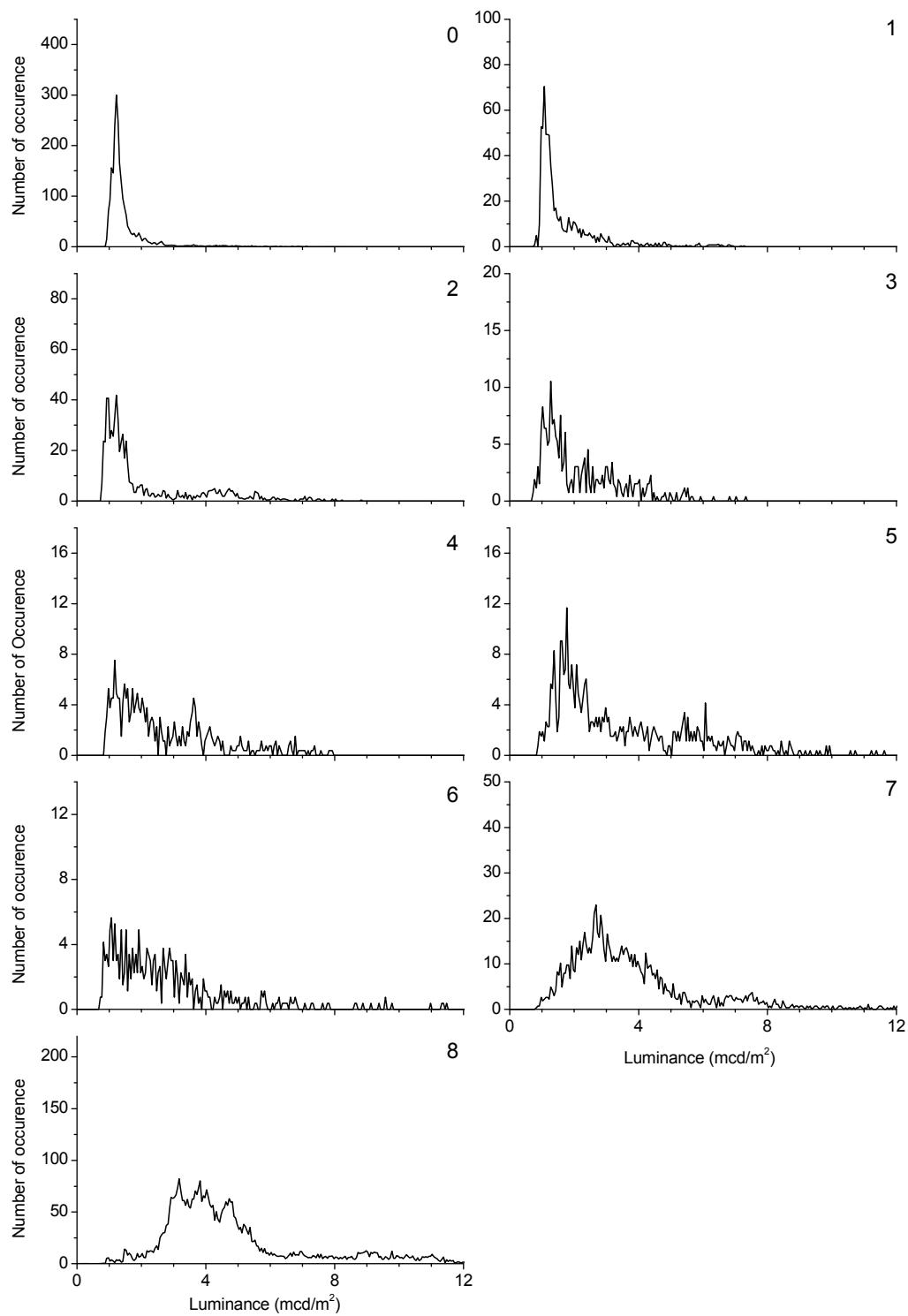

Figure 4: Distribution of the luminance at zenith per octa cloud cover. 

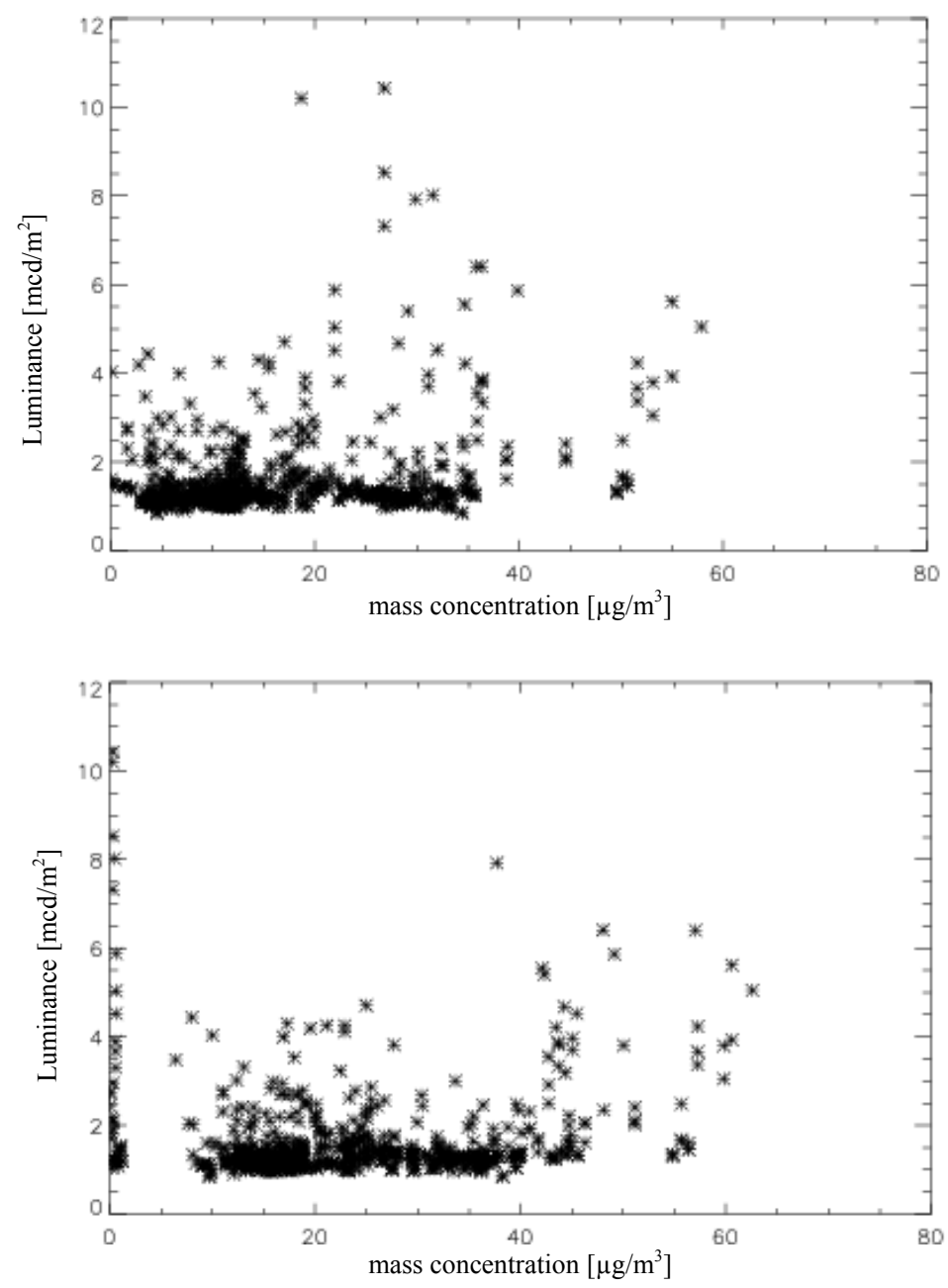

Figure 5: Luminance by the mass concentrations of PM10 (top) and PM2.5 (bottom).

\section{Acknowledgements}

We greatly acknowledge CESAR for hosting the DigiLum instrument, H. Klein Baltink for making available the ceilometer data, W.H. Knap for the APCADA data, A. Apituley for the TEOM data and F.C. Bosveld for the Vaisala data.

\section{References}

[1] Rich. C. \& Longcore, T., Ecological Consequences of Artificial Night Lighting, Island Press, 2006. 
[2] Lawton, J., Artificial Light in the Environment, The Royal Commission on Environmental Pollution, 2009.

[3] Chepesiuk, R., Missing the Dark; Health Effects of Light Pollution, Environmental Health Perspectives, 117(1), pp A20-A27, 2009.

[4] Council of Europe, Parliamentary Assembly, Resolution 1776, Noise and light pollution, 2010.

[5] Cinzano, P., Falchi, F., Elvidge, C.D. \& Baugh, K.E., The artificial night sky brightness mapped from DMSP satellite Operational Linescan System measurements, Mon. Not. R. Astron. Soc. 318, pp. 641-657, 2000.

[6] Cinzano, P., Falchi, F. \& Elvidge, C.D., Naked-eye star visibility and limiting magnitude mapped from DMSP-OLS satellite data, Mon. Not. R. Astron. Soc. 323, pp. 34-46, 2001.

[7] Cinzano, P., Falchi, F. \& Elvidge, C.D., The first World Atlas of the artificial night sky brightness, Mon. Not. R. Astron. Soc. 328, pp. 689-707, 2001.

[8] Lee, T.E., Miller, S.D., Turk, F.J., Schueler, C., Julian, R., Deyo, S., Dills, P. \& Wang, S., The NPOESS VIIRS Day/Night Visible Sensor, Am. Met. Soc., pp. 191-199, 2006.

[9] NPP, http://npp.gsfc.nasa.gov/index.html

[10] CIE, Spatial distribution of daylight -- CIE standard general sky, ISO 15469:2004 (CIE S 011/E:2003).

[11] CESAR, http://www.cesar-observatory.nl

[12] Treanor, P.J.S.J., A simple propagation law for artificial night-sky illumination, The Observatory, pp. 117-120, 1973.

[13] Garstang, R.H., Model for artificial night-sky illumination, Astr. Soc. Of the Pacific, 98, pp. 364-375, 1986.

[14] Falchi, F. \& Cinzano, P., Maps of artificial sky brightness and upward emission in Italy from DMSP satellite measurements, Mem. Soc. Astro. It., 71, pp. 139-15, 2000.

[15] Kerola, D.X., Modelling artificial night-sky brightness with a polarized multiple scattering radiative transfer computer code, Mon. Not. R. Astron. Soc., 365, pp. 1295-1299, 2006.

[16] CIE, Photometry - the CIE system of physical photometry, ISO 23539, 2005.

[17] Vaisala, http://www.vaisala.com

[18] Duerr, B. \& Philipona, R., Automatic cloud amount detection by surface longwave downward radiation measurements, J. Geophys. Res., 109, D05201, 2004.

[19] TEOM, http:/www.thermoscientific.com/wps/portal/ts/products/detail? navigationId $=$ L10405\& categoryId $=89579 \&$ productId $=11960558$.

[20] FDMS, http:/www.thermoscientific.com/wps/portal/ts/products/detail? productId $=11960562$.

[21] Vaisala FD12P, http:/www.vaisala.com/en/tabcontentadmin/Pages/ FD12P.aspx.

[22] KNMI, http://www.knmi.nl/. 